\title{
Anticoagulant therapy in acute respiratory distress syndrome
}

\author{
Marta Camprubí-Rimblas ${ }^{1,2}$, Neus Tantinyà ${ }^{3}$, Josep Bringué ${ }^{1,2,3}$, Raquel Guillamat-Prats ${ }^{1,3}$, Antonio \\ Artigas ${ }^{1,2,3,4}$ \\ ${ }^{1}$ Institut d'Investigació i Innovació Parc Tauli (I3PT), Sabadell, Spain; ${ }^{2}$ Universitat Autònoma de Barcelona, Bellaterra, Spain; ${ }^{3}$ Centro de \\ Investigaciones Biomédicas en Red de Enfermedades Respiratorias (CIBERES), Madrid, Spain; ${ }^{4}$ Critical Care Center, Corporació Sanitària \\ Universitaria Parc Taulí, Sabadell, Spain \\ Contributions: (I) Conception and design: A Artigas, M Camprubí-Rimblas; (II) Administrative support: None; (III) Provision of study materials or \\ patients: None; (IV) Collection and assembly of data: J Bringué, N Tantinyà; (V) Data analysis and interpretation: A Artigas, R Guillamat-Prats; (VI) \\ Manuscript writing: All authors; (VII) Final approval of manuscript: All authors. \\ Correspondence to: Antonio Artigas. Corporació Sanitària Universitària Parc Taulí, Parc Taulí 1, 08208 Sabadell, Spain. Email: aartigas@tauli.cat.
}

\begin{abstract}
Acute respiratory distress syndrome (ARDS) presents a complex pathophysiology characterized by pulmonary activated coagulation and reduced fibrinolysis. Despite advances in supportive care of this syndrome, morbidity and mortality remains high, leading to the need of novel therapies to combat this disease. Focus these therapies in the inhibition of ARDS development pathophysiology is essential. Beneficial effects of anticoagulants in ARDS have been proved in preclinical and clinical trials, thanks to its anticoagulant and anti-inflammatory properties. Moreover, local administration by nebulization in the alveolar compartment increases local efficacy and does not produce systemic bleeding. In this review the coagulation and fibrinolytic pathway and its pharmacological targets to treat ARDS are summarized.
\end{abstract}

Keywords: Acute respiratory distress syndrome (ARDS); acute lung injury (ALI); nebulization; inhalation; coagulation; fibrinolysis

Submitted Dec 08, 2017. Accepted for publication Dec 28, 2017.

doi: 10.21037/atm.2018.01.08

View this article at: http://dx.doi.org/10.21037/atm.2018.01.08

\section{Introduction}

Acute respiratory distress syndrome (ARDS) is an acute respiratory failure that develops in patients of all ages $(1,2)$ and originates from multiple insults that damage directly or indirectly the lungs, such as pneumonia or sepsis (3).

Supportive care to avoid worsening lung injury and improve ARDS outcomes are currently applied, such as mechanical ventilation (4), prone positioning (5) and neuromuscular blockers (6). Nevertheless, morbidity and mortality remain high (35-40\%) (2), and new therapies focused in the pathophysiology of ARDS development are required (7).

The lungs of ARDS patients are characterized by inflammation and increased procoagulant factors, no hydrostatic pulmonary edema and the breakage of the alveolar-capillary barrier, increasing proteins permeability $(8,9)$. This produces the activation of pulmonary macrophages towards a proinflammatory phenotype and an increase of intravascular and extravascular neutrophils, platelets and fibrin, as well as endothelial and epithelial injury.

Given the essential role that coagulation plays in ARDS pathophysiology, this review will focus on the coagulation and fibrinolytic pathways and its pharmacological targets to treat ARDS.

\section{Coagulation and fibrinolysis in the alveolar compartment of ARDS}

Pulmonary coagulopathy in ARDS pathophysiology is characterized by an activated coagulation and reduced fibrinolysis $(10,11)$, similar to the altered coagulation found systemically in septic patients. Different pathways of the coagulation cascade are involved in the pathophysiology of ARDS: tissue factor (TF) pathway, protein $\mathrm{C}$ pathway and 


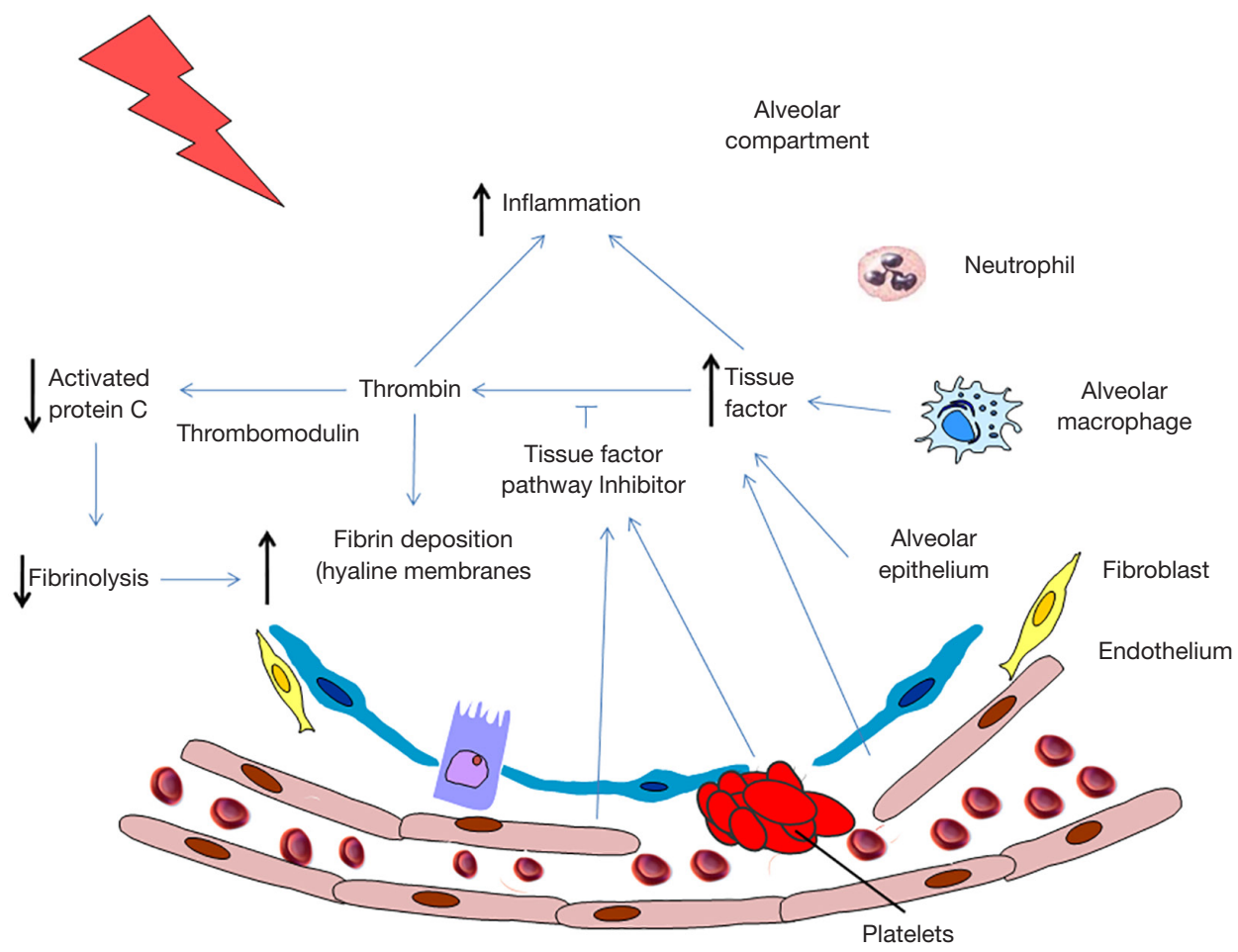

Figure 1 Coagulation and inflammation in the alveolar compartment.

the regulation of fibrinolysis by the plasminogen activator (PA) and inhibitor pathway (Figure 1).

\section{TF pathway}

Activation of TF is a major initiator of extrinsic coagulation cascade. TF is a transmembrane protein that is activated by the binding of factor VIIa on the cell surface. This complex cleaves factor $\mathrm{X}$ producing its activated form, $\mathrm{Xa}$, which brings with it thrombin generation, that is one of the most important procoagulant proteins, and fibrin formation. In normal conditions, there is equilibrium between $\mathrm{TF}$ and TF pathway inhibitor (TFPI) which regulates the initiation of extrinsic coagulation cascade via TF pathway. TFPI is a natural anticoagulant inhibitor produced in the vascular endothelium and on the surface of platelets (12). This inhibitor interferes with the complex TF:VIIa:X inhibiting thrombin production and fibrin deposition. TFPI must bind to $\mathrm{Xa}$ to become active, so this inhibition process just takes place after the initiation of the coagulation pathway (12). Furthermore, the complex VIIa:Xa has a role on inflammation activating protease-activated receptors (PAR-2) on the cell surface of immune cells, platelets and endothelial cells, producing the expression of molecules of adhesion and promoting an inflammatory process (13).

Independently of ARDS etiology, the inflammatory process is one of the major inducers of the coagulation pathway. It has been proved that alveolar macrophages, alveolar epithelial cells and endothelial cells produce TF after being exposed to a proinflammatory stimulus that causes the activation of the transcription factor nuclear factor- $\kappa \mathrm{B}(\mathrm{NF}-\kappa \mathrm{B})(12,13)$.

$\mathrm{TF}$ in the alveolar space is found in alveolar epithelial cells and alveolar macrophages in human lung tissue from ARDS patients (14) and in mice that received lipopolysaccharide (LPS) directly into the lungs (15). In this line, increased TF procoagulant activity is found in the bronchoalveolar lavage (BAL) of ARDS patients and patients with pneumonia without ARDS $(10,16,17)$ and in plasma of septic patients (18). Increased plasma concentrations of TF in ARDS patients are related with poor clinical outcomes (12). The observed changes in TF indicate a common coagulation mechanism in different ARDS etiologies. In pulmonary edema fluid of ARDS patients the levels of TF protein is more than 100-fold higher than in plasma (14). Shaver et al. found out that 
the alveolar epithelium is the major source of TF in acute lung injury (ALI), being protective during this disease, as coagulation and the deposition of fibrin are activated producing a barrier and reducing the alveolar-capillary membrane leakage (19). Bastarache et al. proved that intratracheal $\mathrm{TF}$ administration in a model lacking murine TF reestablished local coagulant activity and reduced haemorrhage and permeability in an ALI model of LPS (20).

Regarding the natural anticoagulant of TF, TFPI levels are increased in the alveolar compartment of ARDS patients, although it does not compensate TF increment, as procoagulant activity predominates. Levels of TFPI are 7 -fold greater in patients at risk and 20-fold more elevated in established ARDS patients (21), and no differences are found in plasma.

\section{Protein C pathway}

Protein $\mathrm{C}$ pathway is also involved in the regulation of coagulation and fibrinolysis. Protein $\mathrm{C}$ is a vitamin $\mathrm{K}$-dependent glycoprotein synthesized by the liver that circulates as a zymogen. Activated protein C (APC) is produced by the thrombin-thrombomodulin (TM) complex on the cell surface. TM is a thrombin receptor that together with thrombin creates a complex that activates protein $\mathrm{C}$, converting thrombin from a procoagulant to an anticoagulant and activating fibrinolysis (22). TM was originally described to be produced by endothelial cells (23) although consequently was either detected in other cell types, including alveolar epithelial cells (24). The endothelial protein $\mathrm{C}$ receptor (EPCR) is another cell surface protein that potentiates activation of protein $\mathrm{C}$ while binding to TM-thrombin complex.

APC presents anticoagulant properties through proteolytically inactivating factors Va and VIIIa, which suppress thrombin formation, and promotes fibrinolysis by neutralizing PA inhibitor-1 (PAI-1). A link between inflammation and coagulation is produced because of the ability of thrombin to activate PAR-1, 3 and 4, and of factor Xa to activate PAR-2, raising the production of inflammatory genes and increasing the activation and recruitment of neutrophils and platelets into the lung (13). Thus, by suppressing thrombin through APC an anticoagulant and anti-inflammatory effects are produced. On the other hand, APC presents anti-inflammatory functions through the suppression of proinflammatory cytokines released by neutrophils $(25,26)$ and has antiapoptotic functions through p53 inhibition.

In normal conditions, human alveolar epithelial cells are able to activate protein $\mathrm{C}$ and express TM and EPCR, which enhances APC. In response to an injurious stimulus, alveolar epithelial cells release TM and EPCR from the cell surface, due to a metalloproteolytic process, reducing the ability of these cells to activate protein C (27) and promoting a procoagulant state and the inhibition of fibrinolysis.

Plasma levels of protein C are reduced in ARDS patients, presenting lower levels in the alveolar compartment (24), especially those patients presenting phenotype 2 (28). In pulmonary edema from ARDS patients, TM is 2-fold higher than in ARDS plasma, and more than 10-fold higher than in normal plasma $(24,29)$. Further, higher plasma levels of soluble TM are related with increased mortality in ARDS (30) and genetic variants in TM and EPCR genes are associated with mortality in ARDS (31). The low protein $\mathrm{C}$ levels and high TM levels in the alveolar compartment provide further support to the growing of evidence that the alveolus is a procoagulant, antifibrinolytic environment in ARDS (32). The protein C system may be a potential therapeutic target in patients with ARDS (12).

\section{Plasminogen activator and inbibitor patbway}

The activation of coagulation and fibrinolysis drives the deposition of fibrin into the lung. PA, which can be urokinase-type PA (uPA) or tissue-type PA (tPA), drive the conversion of plasminogen to plasmin, a fibrinolytic enzyme. This conversion is neutralized by PAI-1.

Alveolar macrophages, endothelial cells and alveolar epithelial cells are sources of PA and PAI-1. When stimulated with a proinflammatory stimulus, alveolar macrophages express higher levels of PAI-1, and endothelial cells express less tPA, resulting in increased fibrinolysis inhibition (25). In patients with ARDS fibrinolysis is reduced, as the levels of PAI- 1 are increased in both plasma and edema fluid, presenting a correlation with mortality $(17,33)$.

\section{Coagulation and fibrinolysis as pharmacological targets for ARDS}

Increased procoagulant activity in the alveolar compartment is evident as higher levels of thrombin generation, soluble TF, and factor VIIa are found in BAL fluid from ARDS 
patients, together with elevated levels of PAI-1, indicating reduced fibrinolysis activity (17). Pharmacological targets for the coagulation cascade and fibrinolytic pathway might be promising candidates for ARDS treatment and prevention.

\section{TFPI}

A treatment for ARDS could be TFPI due to its functions on the coagulant pathway. Neutralize TF activation with TFPI administration diminishes coagulation and cell injury in a septic model in baboons (34) and reduces pulmonary injury and coagulation in a model of LPS through inhibiting leukocytes activation (35). Furthermore, inactivated factor VIIa (VIIai) was developed as an anticoagulant, proving protective effects in a model of sepsis in baboons (36). In a direct and indirect rat model of ALI, nebulized recombinant human TFPI seem feasible and safe (37). It decreased pulmonary and systemic coagulation in both models, although just in the model receiving intratracheal $P$. aeruginosa the pulmonary inflammation was decreased (37).

A phase III clinical trial of intravenous recombinant TFPI failed in reducing mortality in sepsis (38) and severe community-acquired pneumonia (39). Given the positive results obtained with nebulized recombinant human TFPI in preclinical models, further investigation should focus on this form of delivery.

\section{APC}

Nebulized APC administration in animal models of ALI diminishes lung injury (40-42), reduces pulmonary coagulopathy $(43,44)$, stimulates fibrinolysis $(45)$, reduces inflammation $(40,45,46)$ and ameliorates oxygenation $(40,43)$. Systemic coagulation was only decreased in one of the studies with pulmonary infection (43).

In a patient with ARDS that received inhaled APC (Drotrecogin alpha activated), the alveolar compartment resulted with anticoagulant, profibrinolytic and antiinflammatory effects $(26,47)$. Also, inhaled APC reduced neutrophils recruitment in the alveolar space, and did not produce nor local nor systemic adverse effects. Unfortunately, the negative results obtained in the PROWESS-Shock trial, a phase III trial of 1,967 patients with severe sepsis receiving intravenous recombinant human APC (rhAPC) (48), together with the removal of APC from the market ended with the use of APC (7).

\section{$T M$}

ART-123 is a recombinant human soluble TM that through its anticoagulant and anti-inflammatory effect has been proved to improve disseminated intravascular coagulation in animal models and clinical studies (49-52). Furthermore, in a model of cecal ligation and puncture induced sepsis, ART-123 inhibited proinflammatory cytokines and ameliorated survival. In a model of endotoxemia induced by LPS, intravenous ART-123 reduced HMGB1 plasma levels and mortality (53). Indeed, in a phase II study, intravenously administered ART- 123 proved to be safe and effective in patients with sepsis-associated disseminated intravascular coagulation, reducing prothrombin fragment and thrombin-antithrombin (AT) complex concentrations (54). Moreover, in a retrospective study of intravenously combined therapy with sivelestat and recombinant human soluble TM, beneficial effects on survival of patients with ARDS and disseminated intravascular coagulation were suggested (55). At the moment there is an ongoing phase III study of intravenous ART-123 in septic shock patients with disseminated intravascular coagulation and multiorgan failure.

\section{$A T$}

AT, also termed heparin cofactor II or AT III (ATIII) is a broad-spectrum serine protease inhibitor. ATIII neutralizes several enzymes in the coagulation cascade, including thrombin and factor Xa, iXa, Xia and XIIa (56,57).

ATIII contains a heparin-binding domain at its active site. Heparin enhances the inhibitory activity of ATIII of the procoagulant proteins of the coagulation pathway. ATIII also has several indirect anti-inflammatory properties mediated through prostacyclin release $(57,58)$.

Thrombin is increased in the injured lungs of patients with clinical disorders resulting in ALI/ARDS (58-60). Different therapeutic strategies with ATIII have been tested in experimental models and in patients with severe sepsis for restoring the natural anticoagulant cascades. In LPS-induced lung injury, intravenous ATIII has been shown to reduce vascular injury, leukocyte accumulation, and vascular permeability (56-58). Furthermore, in lung injury pneumonia induced by intratracheally $S$. pneumoniae, the pretreatment of nebulized ATIII attenuated pulmonary coagulopathy and fibrinolysis, reduced bacterial outgrowth, decreased inflammation and did not produce systemic bleeding (46). In models of $P$. aeruginosa (43) and 
endotoxemia (44) nebulized ATIII reduced pulmonary coagulation and did not affect systemic coagulation.

Currently, nebulized ATIII has not been administered in any clinical trial. As explained above, preclinical studies with combined ATIII and heparin have also been performed with positive results.

\section{Heparin}

Heparin is a potent natural anticoagulant produced by mast cells in the intestine or lungs, basophils in the blood and endothelial cells (61). This glycosaminoglycan is extensively applied in the clinics for its anticoagulant properties. It potentiates ATIII inhibitory activity in the coagulation pathway and acts through other serine protease inhibitors such as protein $\mathrm{C}$ inhibitor and TFPI (56).

In direct and indirect ARDS, previous studies pointed out that heparin diminishes lung injury, although it produces systemic bleedings. Local administration of heparin for example by nebulization might prevent systemic effects and increase its effectiveness (11). Nebulized heparin ameliorated oxygenation in a model of smoke inhalation and sepsis (62). In preclinical and clinical studies inhaled anticoagulants (heparin, heparinoids, ATs, or fibrinolytics such as tissue PA) favored survival (63).

Furthermore, heparin presents anti-inflammatory activities (64). Heparin was found to inhibit the NF- $\kappa \mathrm{B}$ pathway and decrease the expression of proinflammatory mediators in human alveolar macrophages treated with LPS (65-67) and reduce NF-kB pathway in alveolar cells (67) in vitro. However, studies in in vivo models of ALI present controversial results about the anti-inflammatory effect of heparin. On the one hand, in an animal model of endotoxemia $(43,44)$ and pneumonia $(46)$ the positive effect of nebulized heparin in coagulopathies was confirmed, although no changes on inflammation were found. On the other hand, the administration of nebulized heparin in an ALI rat model induced by intratracheal LPS diminished procoagulant and proinflammatory markers in lung tissue and the expression of NF- $\kappa \mathrm{B}$ and TGF- $\beta$ effectors in alveolar macrophages (68). Also, heparin reduced the recruitment of neutrophils into the alveolar space and edema, without producing systemic bleedings (68). The difference on these results could be attributed to the different timing and dosage of heparin.

Clinical studies with nebulized heparin administered to ARDS patients, did not present adverse effects, attenuated pulmonary coagulopathy and reduced the days of mechanical ventilation (69-71). A recent multicenter trial, HEPBURN, focused in the safety and efficacy of burn patients receiving nebulized heparin, was stopped due to an elevated systemic clotting time $(72,73)$. No convincing benefit of heparin nebulization was found under mechanical ventilation (74) or for prophylaxis for pneumonia patients receiving mechanical ventilation $(75,76)$. In 16 patients with ventilator-induced lung injury, heparin was nebulized proving safety and increasing the number of ventilator-free days (77).

The safety and efficacy of heparin as a treatment for the different etiologies of ARDS needs further investigation, as data is very limited.

\section{$P A$}

Preclinical models support the use of PA for ARDS $(78,79)$, although clinical studies with trauma or septic patients that received intravenous $\mathrm{uPA}, \mathrm{tPA}$ or streptokinase presented higher risk of bleeding $(80,81)$. Nebulization of tPA could maintain its properties while avoid systemic adverse effects (81-84).

\section{Combined therapies}

Until now we have focused on single anticoagulant therapies, but studies were nebulized heparin has been combined with other drugs also proved benefit in ARDS. A preclinical model of combined aerosolized recombinant human AT and heparin in a sheep with burn and smoke inhalation reduced pulmonary pathophysiology (85). Moreover, intravenous recombinant human AT together with aerosolized heparin diminished the lung injury in a model of sheep with burn and smoke inhalation (86). Intravenous AT together with nebulized heparin and $\mathrm{PAA}$ in a model of burn smoke inhalation, sheep restored gas exchange but did not produce changes in inflammation (87).

Aerosolized heparin and $\mathrm{N}$-acetylcysteine diminished lung injury in ventilated smoke inhalation ARDS patients (88) and reduced duration of mechanical ventilation in burn inhalation injury (89). No drug incompatibilities were found in a case of a patient with smoke inhalation injury receiving nebulized heparin with $\mathrm{N}$-acetylcysteine and epoprostenol (90). Nebulized heparin in burn patients together with a beta-agonist and a mucolytic diminished duration of mechanical ventilation, was safe and no bleeding events were recorded (91). 


\section{Future directions}

New therapies based on the pathophysiological processes of ARDS development are need due to the high morbidity and mortality underlying this disease. Activated coagulation and reduced fibrinolytic activity are intrinsic to ARDS. Preclinical and clinical trials show beneficial effects of anticoagulants in ARDS, although results are controversial. Local treatment in the alveolar compartment, through anticoagulants nebulization, raises its effects and avoids systemic bleedings. Nebulization of tPA or TFPI could maintain its properties while avoid systemic adverse effects, further investigation should focus on this form of delivery. However, we should not forget that animal models mimic human ARDS only in part, and that this could affect the relevance of the data. Furthermore, we should have in mind that the time to initiate a treatment is decisive.

The etiology of ARDS pathophysiology is diverse. Identify subtypes in ARDS heterogeneity might help to predict responsiveness to a specific treatment. The use of intravenous ART-123 in a subtype of ARDS patients should be further investigated. ARDS is a complex disease regarding its pathophysiology, so the unique or combined therapy should face different pathways and processes to ameliorate patient's outcomes. The nebulization of ATIII and heparin combined or alone in a subtype of patients most likely to respond to the appropriate anticoagulant should be either studied.

\section{Acknowledgements}

This work was partially supported by Fundació Parc Taulí, CIBERES and the Spanish Society of Intensive Care Medicine SEMICYUC. Furthermore, Dr. Artigas received a research grant and award from Grifols.

\section{Footnote}

Conflicts of Interest: The authors have no conflicts of interest to declare.

\section{References}

1. Bellani G, Laffey JG, Pham T, et al. Epidemiology, Patterns of Care, and Mortality for Patients With Acute Respiratory Distress Syndrome in Intensive Care Units in 50 Countries. JAMA 2016;315:788-800.

2. Matthay MA, Ware LB, Zimmerman GA. The acute respiratory distress syndrome. J Clin Invest 2012;122:2731-40.

3. Ware LB. Pathophysiology of acute lung injury and the acute respiratory distress syndrome. Semin Respir Crit Care Med 2006;27:337-49.

4. Acute Respiratory Distress Syndrome Network, Brower RG, Matthay MA, et al. Ventilation with lower tidal volumes as compared with traditional tidal volumes for acute lung injury and the acute respiratory distress syndrome. N Engl J Med 2000;342:1301-8.

5. Guérin C, Reignier J, Richard JC, et al. Prone positioning in severe acute respiratory distress syndrome. $\mathrm{N}$ Engl J Med 2013;368:2159-68.

6. Papazian L, Forel JM, Gacouin A, et al. Neuromuscular blockers in early acute respiratory distress syndrome. $\mathrm{N}$ Engl J Med 2010;363:1107-16.

7. Artigas A, Camprubí-Rimblas M, Tantinyà N, et al. Inhalation therapies in acute respiratory distress syndrome. Ann Transl Med 2017;5:293.

8. Gonzales JN, Lucas R, Verin AD. The Acute Respiratory Distress Syndrome: Mechanisms and Perspective Therapeutic Approaches. Austin J Vasc Med 2015;2. pii: 1009.

9. Ware LB, Matthay MA. The acute respiratory distress syndrome. N Engl J Med 2000;342:1334-49.

10. Schultz MJ, Millo J, Levi M, et al. Local activation of coagulation and inhibition of fibrinolysis in the lung during ventilator associated pneumonia. Thorax 2004;59:130-5.

11. Tuinman PR, Dixon B, Levi M, et al. Nebulized anticoagulants for acute lung injury - a systematic review of preclinical and clinical investigations. Crit Care 2012;16:R70.

12. MacLaren R, Stringer KA. Emerging role of anticoagulants and fibrinolytics in the treatment of acute respiratory distress syndrome. Pharmacotherapy 2007;27:860-73.

13. Frantzeskaki F, Armaganidis A, Orfanos SE. Immunothrombosis in Acute Respiratory Distress Syndrome: Cross Talks between Inflammation and Coagulation. Respiration 2017;93:212-25.

14. Bastarache JA, Wang L, Geiser T, et al. The alveolar epithelium can initiate the extrinsic coagulation cascade through expression of tissue factor. Thorax 2007;62:608-16.

15. Wygrecka M, Markart P, Ruppert C, et al. Compartmentand cell-specific expression of coagulation and fibrinolysis factors in the murine lung undergoing inhalational versus intravenous endotoxin application. Thromb Haemost 2004;92:529-40. 
16. Idell S, Gonzalez K, Bradford H, et al. Procoagulant activity in bronchoalveolar lavage in the adult respiratory distress syndrome. Contribution of tissue factor associated with factor VII. Am Rev Respir Dis 1987;136:1466-74.

17. Günther A, Mosavi P, Heinemann S, et al. Alveolar fibrin formation caused by enhanced procoagulant and depressed fibrinolytic capacities in severe pneumonia. Comparison with the acute respiratory distress syndrome. Am J Respir Crit Care Med 2000;161:454-62.

18. Gando S, Nanzaki S, Morimoto Y, et al. Systemic activation of tissue-factor dependent coagulation pathway in evolving acute respiratory distress syndrome in patients with trauma and sepsis. J Trauma 1999;47:719-23.

19. Shaver CM, Grove BS, Putz ND, et al. Regulation of alveolar procoagulant activity and permeability in direct acute lung injury by lung epithelial tissue factor. Am J Respir Cell Mol Biol 2015;53:719-27.

20. Bastarache JA, Sebag SC, Clune JK, et al. Low levels of tissue factor lead to alveolar haemorrhage, potentiating murine acute lung injury and oxidative stress. Thorax 2012;67:1032-9.

21. Sabharwal AK, Bajaj SP, Ameri A, et al. Tissue factor pathway inhibitor and von Willebrand factor antigen levels in adult respiratory distress syndrome and in a primate model of sepsis. Am J Respir Crit Care Med 1995;151:758-67.

22. Levi M, Schultz M, van der Poll T. Coagulation biomarkers in critically ill patients. Crit Care Clin 2011;27:281-97.

23. Conway EM. Thrombomodulin and its role in inflammation. Semin Immunopathol 2012;34:107-25.

24. Ware LB, Fang X, Matthay MA. Protein C and thrombomodulin in human acute lung injury. Am J Physiol Lung Cell Mol Physiol 2003;285:L514-21.

25. Ware LB, Bastarache JA, Wang L. Coagulation and fibrinolysis in human acute lung injury--new therapeutic targets? Keio J Med 2005;54:142-9.

26. Puig F, Fuster G, Adda M, et al. Barrier-protective effects of activated protein $\mathrm{C}$ in human alveolar epithelial cells. PloS One 2013;8:e56965.

27. Wang L, Bastarache JA, Wickersham N, et al. Novel role of the human alveolar epithelium in regulating intra-alveolar coagulation. Am J Respir Cell Mol Biol 2007;36:497-503.

28. Calfee CS, Delucchi K, Parsons PE, et al. Subphenotypes in acute respiratory distress syndrome: latent class analysis of data from two randomised controlled trials. Lancet Respir Med 2014;2:611-20.
29. Ware LB, Camerer E, Welty-Wolf K, et al. Bench to bedside: targeting coagulation and fibrinolysis in acute lung injury. Am J Physiol Lung Cell Mol Physiol 2006;291:L307-11.

30. Sapru A, Calfee CS, Liu KD, et al. Plasma soluble thrombomodulin levels are associated with mortality in the acute respiratory distress syndrome. Intensive Care Med 2015;41:470-8.

31. Sapru A, Liu KD, Wiemels J, et al. Association of common genetic variation in the protein $C$ pathway genes with clinical outcomes in acute respiratory distress syndrome. Crit Care 2016;20:151.

32. Idell S. Anticoagulants for acute respiratory distress syndrome: can they work? Am J Respir Crit Care Med 2001;164:517-20.

33. Prabhakaran P, Ware LB, White KE, et al. Elevated levels of plasminogen activator inhibitor-1 in pulmonary edema fluid are associated with mortality in acute lung injury. Am J Physiol Lung Cell Mol Physiol 2003;285:L20-8.

34. Creasey AA, Chang AC, Feigen L, et al. Tissue factor pathway inhibitor reduces mortality from Escherichia coli septic shock. J Clin Invest 1993;91:2850-60.

35. Enkhbaatar P, Okajima K, Murakami K, et al. Recombinant tissue factor pathway inhibitor reduces lipopolysaccharideinduced pulmonary vascular injury by inhibiting leukocyte activation. Am J Respir Crit Care Med 2000;162:1752-9.

36. Carraway MS, Welty-Wolf KE, Miller DL, et al. Blockade of tissue factor: treatment for organ injury in established sepsis. Am J Respir Crit Care Med 2003;167:1200-9.

37. van den Boogaard FE, Hofstra JJ, Brands X, et al. Nebulized Recombinant Human Tissue Factor Pathway Inhibitor Attenuates Coagulation and Exerts Modest Antiinflammatory Effects in Rat Models of Lung Injury. J Aerosol Med Pulm Drug Deliv 2017;30:91-9.

38. Abraham E, Reinhart K, Opal S, et al. Efficacy and safety of tifacogin (recombinant tissue factor pathway inhibitor) in severe sepsis: a randomized controlled trial. JAMA 2003;290:238-47.

39. Wunderink RG, Laterre PF, Francois B, et al. Recombinant tissue factor pathway inhibitor in severe community-acquired pneumonia: a randomized trial. Am J Respir Crit Care Med 2011;183:1561-8.

40. Kotanidou A, Loutrari H, Papadomichelakis E, et al. Inhaled activated protein $\mathrm{C}$ attenuates lung injury induced by aerosolized endotoxin in mice. Vascul Pharmacol 2006;45:134-40.

41. Waerhaug K, Kuzkov VV, Kuklin VN, et al. Inhaled aerosolised recombinant human activated protein $\mathrm{C}$ 
ameliorates endotoxin-induced lung injury in anaesthetised sheep. Crit Care 2009;13:R51.

42. Maniatis NA, Letsiou E, Orfanos SE, et al. Inhaled activated protein $\mathrm{C}$ protects mice from ventilator-induced lung injury. Crit Care 2010;14:R70.

43. Cornet AD, Hofstra JJ, Vlaar AP, et al. Nebulized anticoagulants limit coagulopathy but not inflammation in pseudomonas aeruginosa-induced pneumonia in rats. Shock 2011;36:417-23.

44. Hofstra JJ, Vlaar AP, Cornet AD, et al. Nebulized anticoagulants limit pulmonary coagulopathy, but not inflammation, in a model of experimental lung injury. J Aerosol Med Pulm Drug Deliv 2010;23:105-11.

45. Slofstra SH, Groot AP, Maris NA, et al. Inhalation of activated protein $\mathrm{C}$ inhibits endotoxin-induced pulmonary inflammation in mice independent of neutrophil recruitment. Br J Pharmacol 2006;149:740-6.

46. Hofstra JJ, Cornet AD, de Rooy BF, et al. Nebulized antithrombin limits bacterial outgrowth and lung injury in Streptococcus pneumoniae pneumonia in rats. Crit Care 2009; 13:R145.

47. Heslet L, Andersen JS, Sengeløv H, et al. Inhalation of activated protein $\mathrm{C}$ : A possible new adjunctive intervention in acute respiratory distress syndrome. Biologics 2007;1:465-72.

48. Ranieri VM, Thompson BT, Barie PS, et al. Drotrecogin alfa (activated) in adults with septic shock. N Engl J Med 2012;366:2055-64.

49. Nakashima M, Uematsu T, Umemura K, et al. A novel recombinant soluble human thrombomodulin, ART-123, activates the protein $\mathrm{C}$ pathway in healthy male volunteers. J Clin Pharmacol 1998;38:540-4.

50. Nakashima M, Kanamaru M, Umemura K, et al. Pharmacokinetics and safety of a novel recombinant soluble human thrombomodulin, ART-123, in healthy male volunteers. J Clin Pharmacol 1998;38:40-4.

51. Moll S, Lindley C, Pescatore S, et al. Phase I study of a novel recombinant human soluble thrombomodulin, ART123. J Thromb Haemost 2004;2:1745-51.

52. Saito H, Maruyama I, Shimazaki S, et al. Efficacy and safety of recombinant human soluble thrombomodulin (ART-123) in disseminated intravascular coagulation: results of a phase III, randomized, double-blind clinical trial. J Thromb Haemost 2007;5:31-41.

53. Nagato M, Okamoto K, Abe Y, et al. Recombinant human soluble thrombomodulin decreases the plasma highmobility group box-1 protein levels, whereas improving the acute liver injury and survival rates in experimental endotoxemia. Crit Care Med 2009;37:2181-6.

54. Vincent JL, Ramesh MK, Ernest D, et al. A randomized, double-blind, placebo-controlled, Phase $2 \mathrm{~b}$ study to evaluate the safety and efficacy of recombinant human soluble thrombomodulin, ART-123, in patients with sepsis and suspected disseminated intravascular coagulation. Crit Care Med 2013;41:2069-79.

55. Miyoshi S, Ito R, Katayama $\mathrm{H}$, et al. Combination therapy with sivelestat and recombinant human soluble thrombomodulin for ARDS and DIC patients. Drug Des Devel Ther 2014;8:1211-9.

56. Gray E, Hogwood J, Mulloy B. The anticoagulant and antithrombotic mechanisms of heparin. Handb Exp Pharmacol 2012;(207):43-61.

57. Okajima $\mathrm{K}$, Uchiba $\mathrm{M}$. The anti-inflammatory properties of antithrombin III: new therapeutic implications. Semin Thromb Hemost 1998;24:27-32.

58. Uchiba M, Okajima K, Murakami K. Effects of various doses of antithrombin III on endotoxin-induced endothelial cell injury and coagulation abnormalities in rats. Thromb Res 1998;89:233-41.

59. Yamauchi T, Umeda F, Inoguchi T, et al. Antithrombin III stimulates prostacyclin production by cultured aortic endothelial cells. Biochem Biophys Res Commun 1989;163:1404-11.

60. Fourrier F, Chopin C, Huart JJ, et al. Double-blind, placebo-controlled trial of antithrombin III concentrates in septic shock with disseminated intravascular coagulation. Chest 1993;104:882-8.

61. Cornet AD, Smit EG, Beishuizen A, et al. The role of heparin and allied compounds in the treatment of sepsis. Thromb Haemost 2007;98:579-86.

62. Murakami K, McGuire R, Cox RA, et al. Heparin nebulization attenuates acute lung injury in sepsis following smoke inhalation in sheep. Shock 2002;18:236-41.

63. Miller AC, Elamin EM, Suffredini AF. Inhaled anticoagulation regimens for the treatment of smoke inhalation-associated acute lung injury: a systematic review. Crit Care Med 2014;42:413-9.

64. Lever R, Page CP. Novel drug development opportunities for heparin. Nat Rev Drug Discov 2002;1:140-8.

65. Anastase-Ravion S, Carreno MP, Blondin C, et al. Heparin-like polymers modulate proinflammatory cytokine production by lipopolysaccharide-stimulated human monocytes. J Biomed Mater Res 2002;60:375-83.

66. Hochart H, Jenkins PV, Smith OP, et al. Lowmolecular weight and unfractionated heparins induce 
a downregulation of inflammation: decreased levels of proinflammatory cytokines and nuclear factor-kappaB in LPS-stimulated human monocytes. Br J Haematol 2006;133:62-7.

67. Camprubí-Rimblas M, Guillamat-Prats R, Lebouvier T, et al. Role of heparin in pulmonary cell populations in an invitro model of acute lung injury. Respir Res 2017;18:89.

68. Chimenti L, Camprubí-Rimblas M, Guillamat-Prats R, et al. Nebulized Heparin Attenuates Pulmonary Coagulopathy and Inflammation through Alveolar Macrophages in a Rat Model of Acute Lung Injury. Thromb Haemost 2017;117:2125-34.

69. Dixon B, Santamaria JD, Campbell DJ. A phase 1 trial of nebulised heparin in acute lung injury. Crit Care 2008;12:R64.

70. Dixon B, Schultz MJ, Hofstra JJ, et al. Nebulized heparin reduces levels of pulmonary coagulation activation in acute lung injury. Crit Care 2010;14:445.

71. Dixon B, Schultz MJ, Smith R, et al. Nebulized heparin is associated with fewer days of mechanical ventilation in critically ill patients: a randomized controlled trial. Crit Crit Care 2010;14:R180.

72. Glas GJ, Muller J, Binnekade JM, et al. HEPBURN investigating the efficacy and safety of nebulized heparin versus placebo in burn patients with inhalation trauma: study protocol for a multi-center randomized controlled trial. Trials 2014;15:91.

73. Juschten J, Tuinman PR, Juffermans NP, et al. Nebulized anticoagulants in lung injury in critically ill patientsan updated systematic review of preclinical and clinical studies. Ann Transl Med 2017;5:444.

74. Glas GJ, Serpa Neto A, Horn J, et al. Nebulized heparin for patients under mechanical ventilation: an individual patient data meta-analysis. Ann Intensive Care 2016;6:33.

75. IPHIVAP investigators of the Australian and New Zealand Intensive Care Society Clinical Trials Group. Is inhaled prophylactic heparin useful for prevention and management of pneumonia in ventilated ICU patients? J Crit Care 2016;35:231-9.

76. Bandeshe H, Boots R, Dulhunty J, et al. Is inhaled prophylactic heparin useful for prevention and Management of Pneumonia in ventilated ICU patients?: The IPHIVAP investigators of the Australian and New Zealand Intensive Care Society Clinical Trials Group. J Crit Care 2016;34:95-102.

77. Ghiasi F, Sadeghian M, Emami M, et al. A Pilot Study of Nebulized Heparin for Prevention of Ventilator Induced Lung Injury: Comparative Effects with an Inhaled
Corticosteroid. Indian J Crit Care Med 2017;21:634-9.

78. Abraham E, Gyetko MR, Kuhn K, et al. Urokinase-type plasminogen activator potentiates lipopolysaccharideinduced neutrophil activation. J Immunol 2003;170:5644-51.

79. Stringer KA, Bose SK, McCord JM. Antiinflammatory activity of tissue plasminogen activator in the carrageenan rat footpad model. Free Radic Biol Med 1997;22:985-8.

80. Hardaway RM, Harke H, Williams CH. Fibrinolytic agents: a new approach to the treatment of adult respiratory distress syndrome. Adv Ther 1994;11:43-51.

81. Hardaway RM, Harke H, Tyroch AH, et al. Treatment of severe acute respiratory distress syndrome: a final report on a phase I study. Am Surg 2001;67:377-82.

82. Dunn JS, Nayar R, Campos J, et al. Feasibility of tissue plasminogen activator formulated for pulmonary delivery. Pharm Res 2005;22:1700-7.

83. Lackowski NP, Pitzer JE, Tobias M, et al. Safety of prolonged, repeated administration of a pulmonary formulation of tissue plasminogen activator in mice. Pulm Pharmacol Ther 2010;23:107-14.

84. Stringer KA, Tobias M, Dunn JS, et al. Accelerated dosing frequency of a pulmonary formulation of tissue plasminogen activator is well-tolerated in mice. Clin Exp Pharmacol Physiol 2008;35:1454-60.

85. Enkhbaatar P, Cox RA, Traber LD, et al. Aerosolized anticoagulants ameliorate acute lung injury in sheep after exposure to burn and smoke inhalation. Crit Care Med 2007;35:2805-10.

86. Enkhbaatar P, Esechie A, Wang J, et al. Combined anticoagulants ameliorate acute lung injury in sheep after burn and smoke inhalation. Clin Sci (Lond) 2008;114:321-9.

87. Rehberg S, Yamamoto Y, Sousse LE, et al. Advantages and pitfalls of combining intravenous antithrombin with nebulized heparin and tissue plasminogen activator in acute respiratory distress syndrome. J Trauma Acute Care Surg 2014;76:126-33.

88. Miller AC, Rivero A, Ziad S, et al. Influence of nebulized unfractionated heparin and $\mathrm{N}$-acetylcysteine in acute lung injury after smoke inhalation injury. J Burn Care Res 2009;30:249-56.

89. Elsharnouby NM, Eid HE, Abou Elezz NF, et al. Heparin/ $\mathrm{N}$-acetylcysteine: an adjuvant in the management of burn inhalation injury: a study of different doses. J Crit Care 2014;29:182.e1-4.

90. Dube KM, Ditch KL, Hills L. Use of Nebulized Heparin, Nebulized N-Acetylcysteine, and Nebulized 
Epoprostenol in a Patient With Smoke Inhalational Injury and Acute Respiratory Distress Syndrome. J Pharm Pract 2017;30:663-7.

Cite this article as: Camprubí-Rimblas $M$, Tantinyà $N$, Bringué J, Guillamat-Prats R, Artigas A. Anticoagulant therapy in acute respiratory distress syndrome. Ann Transl Med 2018;6(2):36. doi: 10.21037/atm.2018.01.08
91. McIntire AM, Harris SA, Whitten JA, et al. Outcomes Following the Use of Nebulized Heparin for Inhalation Injury (HIHI Study). J Burn Care Res 2017;38:45-52. 